\title{
EDUCACIÓ FÍSICA I PLÀSTICA. ÀREES INTERDISCIPLINÀRIES
}

\author{
Gemma Solé. Professora d'Educació Física. SES Mont-roig
}

\section{Introducció}

Vaig arribar com a especialista d'Educació Física en un centre d'ESO. Per necessitats internes vaig haver de fer un crèdit variable de l'àrea de visual i plàstica. Com que el centre és de nova creació i no disposàvem de material d'educació física, vaig plantejar el crèdit amb la finalitat de construir material per a la meva àrea i, en la mesura del que fos possible, que aquest material s'obtingués a base del reciclatge.

Un dels eixos de l'actual Reforma educativa és la globalització. Partint dels meus coneixements i necessitats a l'hora d'impartir la meva àrea d'educació física, vaig enfocar el crèdit variable de visual i plàstica en la construcció de material per a la meva assignatura.

No m'interessava que els alumnes anessin acumulant nous continguts en la seva estructura cognoscitiva, sinó que la nova matèria d'aprenentatge es relacionés de forma substantiva i no arbitrària amb allò que l'alumne ja sap; idea fonamental de l'actual Reforma educativa, l'aprenentatge significatiu. D'aquesta manera, l'alumne podia aportar a aquest crèdit els sabers que ja tenia.

A nivell pràctic aquest constructivisme va quedar reflectit en els punts:

- L'alumne era el responsable últim del seu procés d'aprenentatge.

- Cada alumne/a partia dels seus camps d'experiència per elaborar-ne de nous.

- El paper del professor era el d'orientar l'activitat constructiva de l'alumne/a, facilitant els recursos perquè poguessin establir lligams entre les seves estructures conceptuals i els nous sabers.

Les implicacions didàctiques d'aquest model d'ensenyament/aprenentatge exigia que jo conegués els coneixements i les habilitats prèvies de l'alumnat. L'observació diària en l'inici de cadascuna de les activitats em va servir d'avaluació inicial; la implicació i el tipus de treball que escollia l'alumne em va servir d'avaluació formativa i l'avaluació sumativa era la presentació dels diferents treballs.

La construcció de material, la seva posada en pràctica i el fet de ser ells mateixos els responsables de les activitats d'aprenentatge van servir com a elements motivadors del mateix crèdit. Per exemple, el treball cooperatiu en la construcció de material més complex com els grans jocs o la construcció de la tanca d'atletisme i l'intercanvi de rols; fer ells mateixos de professors va suposar que l'alumne assumís una major responsabilitat en el procés d'aprenentatge.

La manera d'entendre aquesta globalització va ser a partir del tema, del títol del crèdit: Construïm material per a l'Educació Física, en el qual englobaríem les àrees de visual i plàstica, educació física, tecnologia, matemàtiques i ciències experimentals.

Els alumnes a qui anava dirigit aquest crèdit eren els de $2 n$ d'ESO. Vaig haver de plantejar el crèdit de manera oberta perquè no tenia cap referència dels alumnes al ser nova al centre; així doncs, vaig establir els objectius i continguts, i un seguit d'activitats sense ordre temporal que les aniríem fent seguint el ritme i les aportacions dels mateixos alumnes.

El que podia semblar un plantejament bastant improvisat va resultar ser molt vàlid, ja que els mateixos alumnes van prendre part en la seqüenciació del crèdit. A partir de les activitats que els vaig presentar el primer dia, ells en van proposar de noves i la manera de realitzar-les.

Com que no disposàvem d'un pressupost per a aquest crèdit $i$ tampoc no volia que els alumnes compressin material, vam abordar el tema del reciclatge per tal de resoldre la situació.

Aquest crèdit també permet tractar el treball en la diversitat o bé escollint el tipus d'activitat que anava més d'acord amb les característiques i interessos de cada alumne, o bé fent les tasques que venien més de gust en els treballs de gran grup.

\section{Continguts}

Aquests continguts estan extrets del primer nivell o bé dels exemples de segon nivell de cadascuna de les àrees curriculars.

Visual i Plàstica: Utilització del regle i el compàs. Presentació acurada dels treballs. Utilització correcta dels colors i retoladors. Respecte als companys i les companyes en la proposta d'activitats. Sensibilització per la conservació i el manteniment del material construït.

Educació física: Aprenentatge del joc alternatiu de 


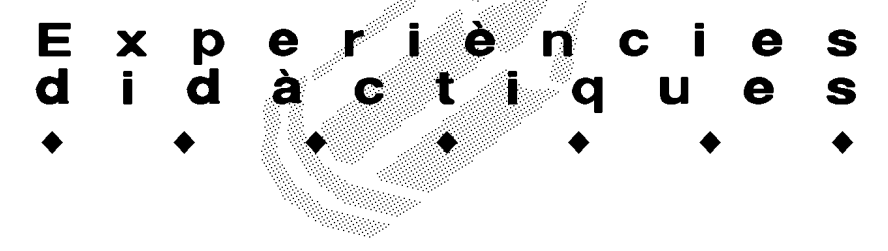

les indiaques. Coneixement dels jocs de taula: parxís, escacs, cartes, tres en ratlla i dominó. Pràctica del joc tradicional de les bitlles. Utilització dels marcadors en les competicions esportives del centre. Treball de l'expressió corporal i dels continguts de concepte en el joc de l'oca. Acceptació de les regles i normes proposades pels alumnes en el joc de l'oca i del monopoly de futbol.

Tecnologia: Utilització de les eines de fusteria en la construcció de la tanca d'atletisme. Consideració de les possibilitats d'aprofundiment dels recursos propis de la zona. Consideració de la necessitat de reciclatge de material. Anàlisi de les vies d'aprofitament del material de desfeta.

Matemàtiques: Construcció de figures geomètriques planes fent ús d'instruments de dibuix. Coneixement dels polígons en el tangram. Utilització de bitllets amb nombres més grans de sis xifres.

Ciències Experimentals: Valoració del reciclatge de materials com a estalvi de primeres matèries. Coneixement i aprofitament dels recursos de l'entorn. Col-laboració en el reciclatge del material. Valoració de l'ús de materials reciclables.

\section{Objectius didàctics}

- Prendre consciència de la necessitat del reciclatge de materials.

- Tenir una actitud positiva en la tasca de construcció de material d'Educació Física.

- Donar importància a la planificació i ordenació del treball en equip, col-laborant-hi activament de forma individual i respectant l'aportació dels companys i companyes.

- Reflexionar sobre problemes com la generació de deixalles i la limitació dels recursos naturals.

- Utilitzar correctament aparells de dibuix i mesura (regle, escaire i compàs) per fer construccions geomètriques planes.

- Manejar amb fluïdesa nombres amb més de sis xifres.

- Aplicar les regles i les normes de diferents jocs de taula.

- Utilitzar l'expressió corporal per fer representacions.

- Emprar tècniques de control corporal per a la realització de qualsevol moviment.

- Cooperar amb els companys per aconseguir fites comunes respectant el resultats en els jocs.

\section{Activitats d'aprenentatge}

\section{Indiaques}

Van ser construïdes amb papers de diari, globus i bosses d'escombraries. Tot aquest material l'aportaven els alumnes. També van portar cinta adhesiva per enganxar les cintes fetes amb bosses d'escombraria que simulaven les plomes.

En parelles, un feia una bola de paper ben arrodonida mentre l'altre tallava la punta del globus que l'obria per posar a dintre la bola de paper. Feien cintes tallant les bosses d'escombraries. S'intercanviaven entre els grups les cintes de colors de diferents tipus de bossa i les enganxaven a la bola de paper que estava dintre del globus amb la cinta adhesiva.

Un cop agafada la dinàmica, en feien unes quantes. Els demanava que tinguessin cura que la bola de paper fos més arrodonida i que les cintes de les bosses d'escombraries anessin d'acord amb el color del globus.

$\mathrm{Hi}$ va haver alumnes que van decorar les indiaques.

L'últim quart d'hora de la classe van anar a fora el pati a estrenar-les.

Marcadors

Amb ordinador vaig fer els números de l'1 al 21 en dos colors i de cada xifra vam fer dues còpies. El treball dels alumnes va consistir a retallar tots els números amb unes mides establertes, enganxar cada número amb el posterior de manera que servís tant per a la gent que juga com per al jutge de taula.

Amb un cartró reciclat d'una impremta vam fer la base del marcador. Posteriorment vam fer dos forats als números i vam col-locar anelles de paper plastificat com a protecció i, amb anelles vam poder fer girar els números del marcador.

\section{Els escacs}

Amb cartró reciclat vam fer la forma d'un quadrat; el vam folrar amb foli i vam dibuixar els quadrats de 8x8 la mesura dels quals depenia de la grandària del cartró. Amb paper de xarol negre vam fer els quadrats negres que anaven enganxant damunt del tauler. Van folrar el tauler amb paper plastificat adhesiu.

Per a les fitxes vaig fer fotocòpies d'un llibre, les van retallar i les van folrar amb paper adhesiu.

Vam aprofitar per jugar al joc i per ensenyar com es jugava als alumnes que no en sabien.

\section{El dominó}

D'un manual vaig fer fotocòpies ampliades de les fitxes, les van retallar, enganxar damunt de cartró reciclat i les van folrar amb paper plastificat adhesiu.

Va ser una activitat senzilla i vaig avaluar el nivell de polidesa amb què treballaven (retallar i folrar).

Vam guardar els dominós en capses de llumins que alguns alumnes van decorar.

\section{El tangram}

Plantejament igual al del dominó: retallar, enganxar damunt de paper reciclat i folrar les figures geomètriques amb paper adhesiu. 


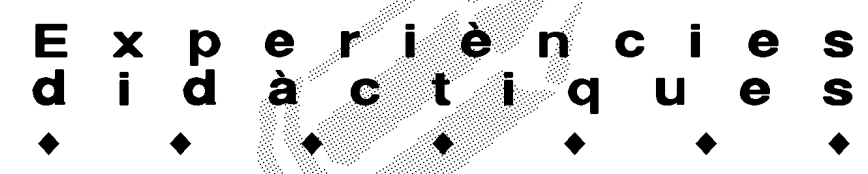

En aquest treball vam aprofitar per realitzar diferents figures geomètriques i figures humanes, pròpies del joc del tangram.

\section{El tres en ratlla}

A partir d'una fotocòpia del joc vaig valorar la faceta decorativa en el tauler i la creativa en les fitxes. Ho podien pintar com volien (llapis, retoladors...) i en la construcció de les fitxes vaig prioritzar que fossin en relleu.

\section{Joc tradicional}

Amb pots de iogurt, cordill i globus d'una pesseta (més petits que els normals), vam construir aquest joc. A la base del iogurt sortia un cordill en l'extrem del qual anava una bola de paper dintre d'un globus (semblant a la indiaca).

Valorava la decoració del pot.

En acabar vam comprovar l'habilitat dels alumnes.

Baralla de cartes

Vaig repartir les 48 cartes de la baralla entre els alumnes del crèdit. Els van tocar dues figures (núm: $1,10,11$ i 12) i dos de la resta de números. Ells podien escollir els pals i intercanviar-se'ls entre ells si volien.

Les cartes es van dibuixar sobre un foli, enganxades en cartró reciclat i folrades amb paper adhesiu.

\section{Bitlles/Cons}

Amb ampolles de llet de litre i mig, vam anar a buscar sorra al barranc del poble. El bitllot era una ampolla de llet d'un litre.

Aquestes mateixes ampolles plenes de sorra em serveixen com a cons en els circuits.

\section{Cèrcols}

Aprofitant que el poble té tradició ciclista, vam anar a la botiga de ciclisme a buscar pneumàtics de bici i en un taller de reparació de cotxes vam agafar pneumàtics de cotxe.

\section{Parxís}

Prenent com a models diferents tipus i mides de parxís, van calcar el tauler, el van pintar, decorar i van fer les fitxes.

\section{GRAN JOC: L'oca esportiva}

Simulant el joc de l'oca tradicional, a cada casella hi ha preguntes teòriques relacionades amb l'educació física o bé activitats pròpies de l'àrea que es poden realitzar dintre de la classe, com per exemple: activitats d'expressió corporal, circuits d'habilitat i d'equilibri amb estris petits, exercicis de punteria, fer abdominals en un temps determinat, fer el pi, destreses de flexibilitat...

Per poder jugar tot el grup classe, vam construir un dau gegant perquè tothom el pogués veure. Està fet amb cartró reciclat, ple de papers de diari col-locats uniformement; en folis van dibuixar les rodones del nombre del dau i està folrat amb paper adhesiu.

La dinàmica del joc és dividir la classe en quatre

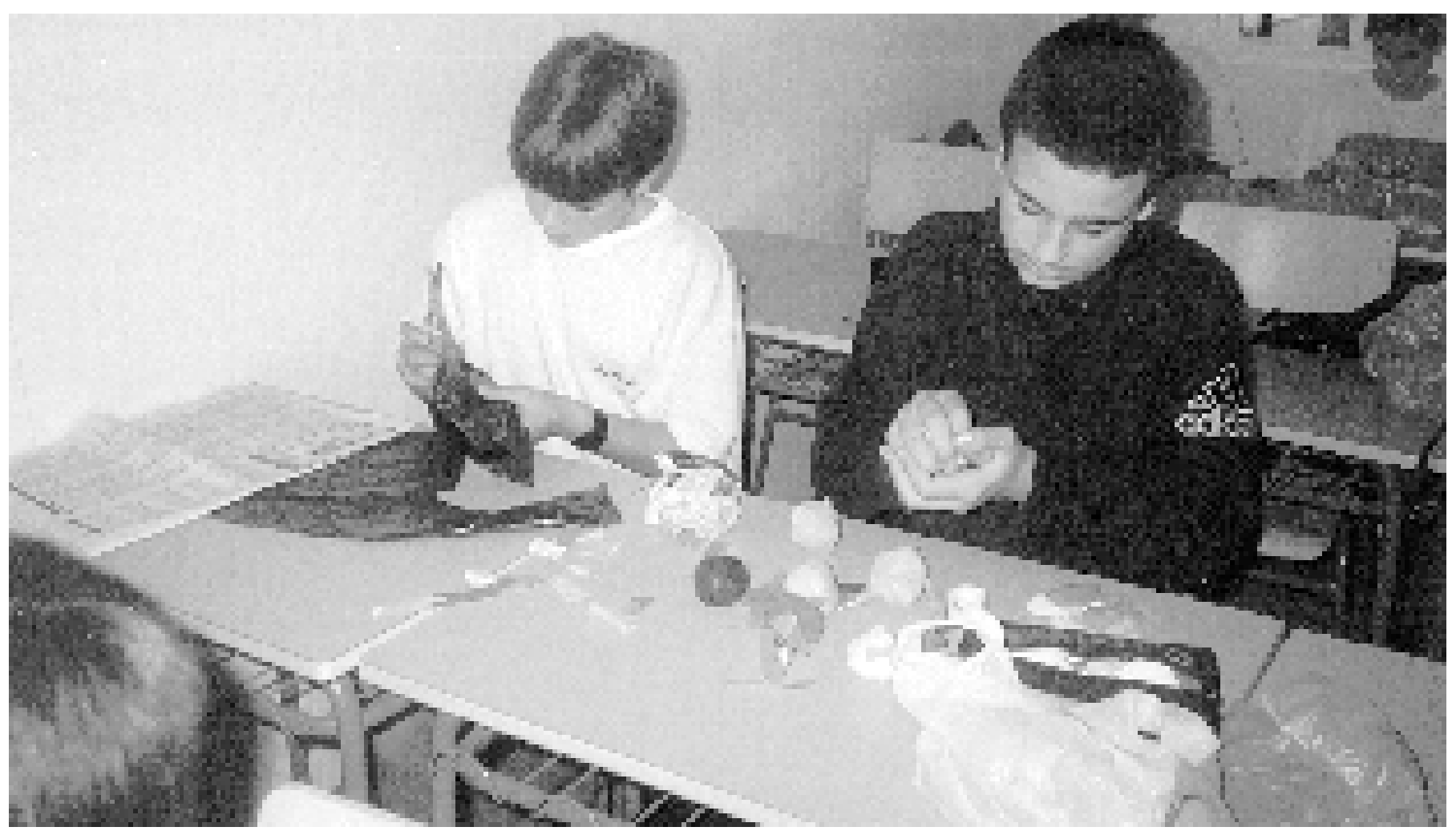




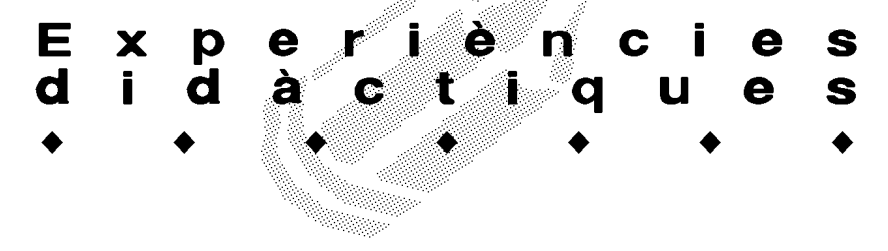

grups, cada grup té un color. Cada cop llença el dau un del grup i la prova l'ha de realitzar qualsevol membre del grup, no necessàriament el/la que tira. Si no assoleixen la prova, retrocedeixen cinc llocs.

Cada cinc caselles hi ha l'oca esportiva que et permet avançar més ràpid. A l'igual que l'oca tradicional, quan caus a l'oca avances fins a la següent i tornes a tirar. futbol

GRAN JOC: Monopoly de jugadors de la lliga de

Volíem fer un monopoly d'esports de compra-venda de jugadors. La primera idea va ser de fer-ho de diferents esports, ja que la fitxa dels jugadors varia molt d'un esport a l'altre. Però davant la dificultat d'obtenir dades reals vam decidir fer el monopoly exclusivament de jugadors de futbol.

Ells van decidir els equips i els jugadors (equival als carrers dels diferents barris) i els entrenadors (les estacions).

Aquí hi va haver una veritable distribució de feines: dos eren els encarregats de fer el tauler gran, altres de pintar els jugadors dels diferents equips, altres de buscar el que valien i establir les clàusules de rescisió.

Per als bitllets vam fer un concurs de disseny, vam votar els que més ens agradaven, vam fer fotocòpies i llavors vam pintar de diferents colors la quantitat del bitllet per diferenciar-los.

La dinàmica del joc amb tota la classe és semblant al de l'oca. Vam dividir la classe en quatre grups. Cada grup un color de fitxa. Vam repartir cinc bitllets dels que havíem fet per a cada grup: un milió, cinc milions, cinquanta milions, cent milions i mil milions.

La forma de jugar és la mateixa que el monopoly tradicional, però en lloc de comprar carrers compren jugadors d'un equip. Les cases són clàusules de rescisió que poden anar ampliant. Quan un alumne cau en una casella d'un jugador que has comprat, ha de pagar segons les clàusules de rescisió que tingui. Si et quedes sense diners, pots hipotecar el jugador. Quan passes per la casella de sortida et donen diners. En Iloc de comprar estacions compres entrenadors. Pots caure en dues caselles de sort i hi ha targetes bones i dolentes.

L'única diferència d'aquest gran joc amb el de l'oca és que és millor jugar-lo amb pocs jugadors i fa falta més d'una hora de classe perquè es fa llarg.

\section{Activitats d'avaluació}

No hi va haver pròpiament cap activitat d'avaluació inicialen el crèdit, tant al primer trimestre com quan el vaig repetir al segon. Les idees dels alumnes i la seva participació en cada una de les activitats em van servir d'avaluació inicial i formativa.
Les reorientacions tant individuals com grupals durant cadascuna de les activitats van servir d'avaluació formativa. El replantejament de les activitats, la recerca de nous materials de l'entorn que podíem reciclar van servir per donar forma a les activitats que inicialment havíem planificat.

La presentació de tots els treballs individuals, la participació en la realització dels grans jocs i l'assoliment de cadascun dels objectius didàctics del crèdit van servir per fer I 'avaluació fina/de cada alumne.

\section{Valoració i perspectives de l'activitat}

Si el proper curs em toqués fer altre cop un crèdit variable de l'àrea de visual i plàstica, el tornaria a fer. No perquè necessités més material del tipus que hem construït, sinó més aviat per la dinàmica que es genera en aquest tipus de crèdit.

La creativitat, l'aprofitament del material disponible, el de l'entorn i el que podem reciclar genera un esperit de tenir cura d'allò que tenim més proper i en podem treure un profit, molts cops inesperat.

Crec que entre els dos trimestres vam fer un gran nombre de material diferent i que he utilitzat, més d'un cop, en les meves classes d'educació física quan la climatologia no acompanyava.

El fet d'haver utilitzat material construït per ells fa que tinguin més cura a l'hora de fer-lo servir.

Aquestes activitats les he vinculat directament amb l'àrea d'educació física per propi interès, però hi ha possibilitats de vincular aquestes activitats amb altres àrees curriculars, per exemple:

Amb les ciències socials, amb el tema de jocs d'arreu del món. Com construir-los, com jugar-hi (reglament), els seus orígens...

Es pot treballar aspectes de l'educació física que tradicionalment es treballen poc o poden tenir un altre caire, com és l'expressió corporal, les danses populars i d'arreu del món. Podem construir els vestits, fer representacions dramàtiques...

Es pot relacionar amb activitats a la natura, com classes d'orientació; construint brúixoles d'aigua i de vent, etc.

Aquestes activitats que es podrien fer i d'altres més relacionades amb l'entorn familiar creen una estructura de vincle família-institut, cada cop més perduda. Per exemple, vam poder construir una tanca d'atletisme perquè un alumne tenia un tiet que era fuster i la vam envernissar amb pintures que ell mateix va portar de casa perquè el seu pare és pintor.

L'ajuda que els alumnes poden demanar als seus pares o familiars més propers crea un vincle que cal potenciar cada cop més. 